\title{
MODELING AND SIMULATION OF THE EFFECT OF MOISTURE CONTENT AND AMBIENT TEMPERATURE ON GAS TURBINE POWER PLANT PERFORMANCE IN UGHELLI, NIGERIA
}

\author{
F. Onoroh ${ }^{1 *}$, M. Ogbonnaya ${ }^{2}$ and U. P. Onochie ${ }^{3}$

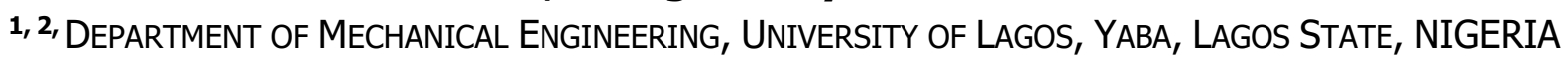 \\ 3, Dept. Of MeChanical Engr'G, Alex EkWueme Fed. Univ., Ndufu-ALIKe IKWo, Ebonyi STATE, NIGERIA \\ E-mail addresses: 1 fonoroh@unilag.edu.ng, ${ }^{2}$ mogbonnaya@unilag.edu.ng, \\ 3 onochieuche@yahoo.com
}

\begin{abstract}
The influence of ambient temperature and moisture content on the performance of Transcorp Power Plant, Ughelli, Delta State, Nigeria was investigated with the aid of a digital psychrometer. The simulation was done using codes developed on MATLAB R2017a and the results show that compressor power consumption increased by $1.65 \%$ for $0.7 \%$ rise in temperature, and $0.50 \%$ for $71.4 \%$ rise in moisture content. The specific fuel consumption also increased with increase in temperature where a $1.71 \%$ rise in ambient temperature resulted in a $0.15 \%$ rise in specific fuel consumption but it decreased by $0.49 \%$ for a $41.7 \%$ rise in moisture content. $A 1.62 \%$ rise in temperature led to a $0.13 \%$ drop in net power output and a $29.4 \%$ rise in moisture content resulted in a $0.48 \%$ drop in net power output. Thus gas turbine plant operates optimally in areas with low ambient temperatures and high moisture content.
\end{abstract}

Keywords: Work ratio, net power, efficiency, moisture content, specific fuel consumption, heat rate.

\section{INTRODUCTION}

Gas Turbines have been used over the years to produce continuous electricity for rural and urban regions and it is viewed as the most fit solution to the increasing electricity demand. Therefore, it is necessary to discover ways to improve output from a gas turbine. Ensuring gas turbines run at maximum efficiency is a primary goal for operators. In the current economic climate, anything that increase productivity and hence profit is clearly welcome, as most of the operating cost of a gas turbine is the cost of the fuel.

The gas turbine compressor is design in such way that the air is compressed with a minimum work input while retaining relatively high efficiency and aerodynamic stability over the operating range [1]. The work outputs also depend on the maximum cycle temperature and pressure ratio, however, higher turbine inlet temperatures are still limited by turbine blade cooling requirement and metallurgical improvements [2]. A schematic diagram of a simple cycle, single shaft gas turbine and the corresponding temperature and entropy diagram is as shown in Figure 1 and Figure 2 respectively.

Operating parameters of ambient temperature, altitude, humidity termed climatic conditions affects the performance of gas turbine units [3][4]. These climatic conditions are worst still dynamic in nature, varying at different times of the day and season [5][6].

\section{THERMODYNAMIC ANALYSIS OF THE GAS TURBINE PLANT}

2.1. Psychrometrics Analysis of moist air

Psychrometrics define the thermodynamic properties of moist air under specified conditions of dry bulb temperature and wet bulb temperature and relative humidity. The amount of moisture in the air is readily obtained as [7]:

$$
\omega=\frac{\dot{m}_{v}}{\dot{m}_{a}}
$$


where $\omega$ equals specific humidity in $\mathrm{kg} / \mathrm{kg}$ dry air, $\dot{m}_{v}$ equals mass flow rate of water vapour in $\mathrm{kg} / \mathrm{s}$ and $\dot{m}_{a}$ equals mass flow rate of dry air in $\mathrm{kg} / \mathrm{s}$. The specific humidity is normally expressed as [7]:

$$
\omega=0.622 \frac{P_{v}}{P_{a}}
$$

According to Dalton's law; the total pressure of the atmospheric air is expressed as:

$$
P=P_{v}+P_{a}
$$

Where $\mathrm{P}$ equals barometric pressure, $P_{v}$ equals partial pressure of water vapour and $P_{a}$ equals partial pressure of dry air in $\mathrm{N} / \mathrm{m}^{2}$.

The relative humidity of the atmosphere is the ratio of the actual partial pressure of the vapour to the partial pressure of the vapour when the air is saturated at the same temperature. Mathematically, it is defined as [8]:

$$
\phi=\frac{\mathrm{P}_{\mathrm{v}}}{\mathrm{P}_{\mathrm{vs}}}
$$

It is also expressed as:

$$
\phi=\frac{\dot{m}_{v}}{\dot{m}_{v s}}
$$

where $\dot{m}_{v s}$ equals mass flow rate of saturated vapour, $\mathrm{kg} / \mathrm{s}$ and $P_{v s}$ equals partial pressure of saturated vapour, $\mathrm{N} / \mathrm{m}^{2}$.

Degree of saturation is defined as:

$$
\mu=\frac{\omega}{\omega_{s}}
$$

where $\omega_{s}$ is the specific humidity at saturation. It is can also be computed from a knowledge

of relative humidity and pressures as:

$$
\mu=\phi\left(\frac{P-P_{v s}}{P-P_{v}}\right)
$$

The three most important variables on which every other properties of moist air depend are, the dry bulb temperature, wet bulb temperature and the barometric pressure or atmospheric pressure. These parameters are readily measured and are used to evaluate the partial pressure of water vapour using Carrier's equation, defined as [9]:

$$
P_{v}=P_{w}-\frac{\left(P-P_{w}\right)\left(t_{d b}-t_{w b}\right)}{1547-1.44 t_{w b}}
$$

$P_{w}$ equals partial pressure of saturated water, $\mathrm{N} / \mathrm{m}^{2}$, $t_{d b}$ equals dry bulb temperature in ${ }^{\circ} \mathrm{C}$, and $t_{w b}$ equals wet bulb temperature, ${ }^{\circ} \mathrm{C}$.

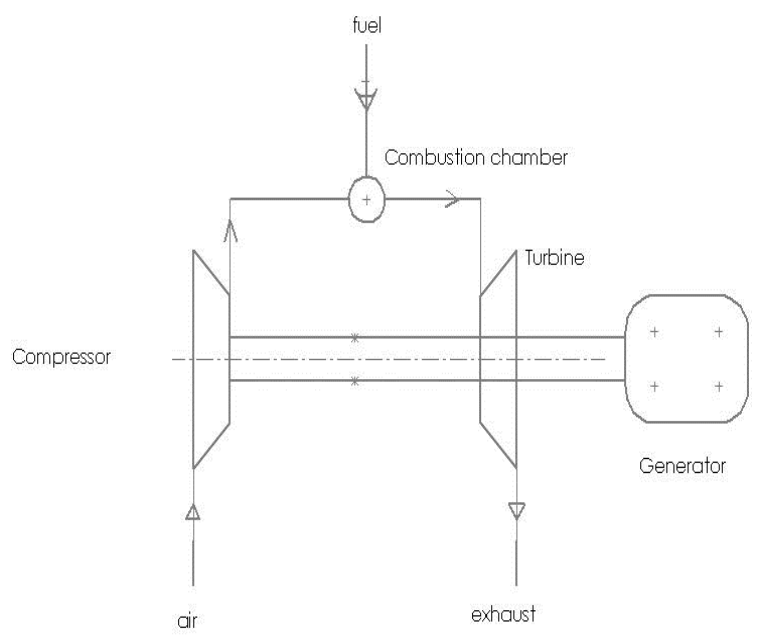

Fig. 1: Single Shaft Gas Turbine

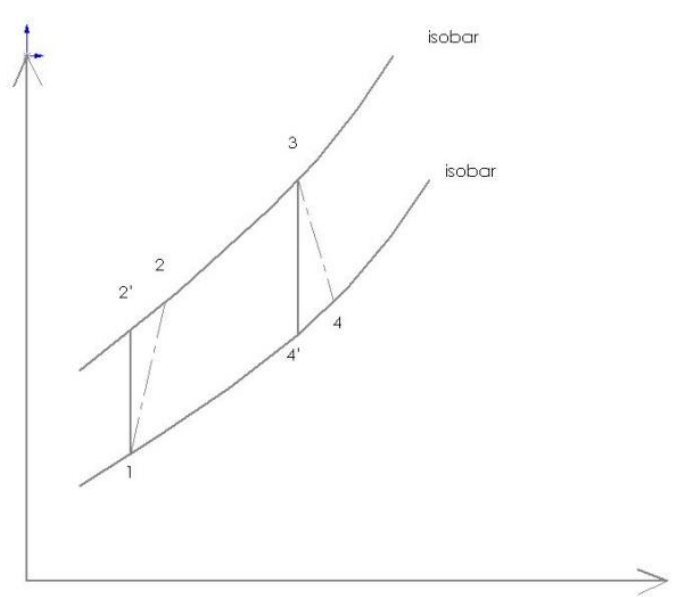

Fig. 2: Gas Turbine $T$-S Diagram

\subsection{Performance criteria of the Gas turbine}

2.2.1. Compressor Power consumption

The power delivered to the compressor by the turbine is defined as [10]:

$$
P_{c}=\dot{m}_{m a} C_{p m a}\left(T_{02}-T_{01}\right)
$$

Where $\dot{m}_{m a}$ equals mass flow rate of moist air in $\mathrm{kg} / \mathrm{s}$ and $C_{p m a}$ equals specific heat capacity at constant pressure of moist air, $\mathrm{N} / \mathrm{m}^{2}, T_{02}$ equals compressed air exit stagnation temperature, ${ }^{\circ} \mathrm{C}$ and $T_{01}$ equals inlet air stagnation temperature, ${ }^{\circ} \mathrm{C}$.

But

$$
\dot{m}_{m a}=\dot{m}_{v}+\dot{m}_{a}
$$

In the light of equation (1) 


$$
\dot{m}_{m a}=\dot{m}_{a}(\omega+1)
$$

Substituting equation (11) in equation (9) yield:

$$
P_{c}=\dot{m}_{a}(\omega+1) C_{p m a}\left(T_{02}-T_{01}\right)
$$

The power consumption can be expressed directly as a function of humidity ratio and ambient temperature as $[11,12]$ :

$$
P_{c}=\dot{m}_{a}(\omega+1) C_{p m a} T_{01}\left(\frac{T_{02}}{T_{01}}-1\right)
$$

The empirical relation to evaluate the specific heat capacity of moist air, $C_{p m a}$, at constant pressure is expressed for the $200 \mathrm{~K}<\mathrm{T}<800 \mathrm{~K}$ [13] as:

$$
\begin{aligned}
& C_{p m a}(T) \\
& =1.0189 \exp 10^{3}-0.13784 T+1.9843 \exp 10^{-4} T^{2} \\
& +4.2399 \exp 10^{-7} T^{3} \\
& -\quad 3.7632 \exp 10^{-10} T^{4}
\end{aligned}
$$

where

$$
T=\frac{T_{02}+T_{01}}{2}
$$

Using the isentropic relation, the temperature gradient across the compressor is obtained as [14], [15]:

$$
T_{02}-T_{01}=\frac{T_{01}}{\mathrm{y}_{c}}\left[\left(\frac{P_{2}}{P_{1}}\right)^{\frac{\gamma_{a}-1}{\gamma a}}-1\right]
$$

Where $\eta_{c}$ is the isentropic efficiency of compression, $P_{2} / P_{1}$ is the compression pressure ratio, $\gamma_{a}$ is the ratio of specific heat capacities of air.

\subsubsection{Combustion heat transfer}

The air from the compressor is fed into the combustion chamber, where a quantity of fuel is introduced and ignited to release large quantum of energy to generate high temperature gaseous mixture. The stoichiometric ratio is approximately 15:1 but the actual fuel ratio would be in the region of $100: 1$ [16].

The heat transfer due to combustion in the combustion chamber by application of the steady flow energy equation is defined as:

$$
Q=\dot{m}_{g} C_{p g}\left(T_{03}-T_{02}\right)
$$

Where $\dot{m}_{g}$ equals mass flow rate of flue gases, $\mathrm{kg} / \mathrm{s}$, $C_{p g}$ equals specific heat capacity of the flue gas, J/kgK, $T_{03}$ equals turbine inlet temperature, ${ }^{\circ} \mathrm{C}$.

But

$$
\dot{m}_{g}=\dot{m}_{m a}+\dot{m}_{f}
$$

Where $\dot{m}_{f}$ is the mass flow rate of fuel, $\mathrm{kg} / \mathrm{s}$. In the light of equation (11) and equation (17), the quantum of heat transfer can be computed as:

$$
Q=\left(\left(\dot{m}_{a}(1+\omega)\right)+\dot{m}_{f}\right) C_{p g}\left(T_{03}-T_{02}\right)
$$

Knowing the fuel gas heat value (FHV), the mass flow rate of fuel flow rate, $\mathrm{m}_{\mathrm{f}}$, can be obtained as;

$$
m_{f}=\frac{Q / F H V}{\eta \text { combustor }}
$$

Where $\eta$ combustor is the combustor efficiency, $Q$ is the quantity of heat supplied.

The specific fuel consumption, sfc, is determined as:

$$
s f c=\frac{3600 m_{f}}{P_{c}}
$$

Where $P_{c}$ equals net power output of the gas turbine. Application of the first law of thermodynamics in the combustor yields the energy balance as [17]:

$$
\dot{m}_{f} F H V=\left(\dot{m}_{a}(1+\omega)+\dot{m}_{f}\right) C_{P g}\left(T_{03}-T_{02}\right)
$$

\subsubsection{Gross power output of turbine}

The gross power output by application of the steady flow energy equation is expressed as:

$$
P_{t}=\dot{m}_{g} C_{p g}\left(T_{03}-T_{04}\right)
$$

From equation (17), the power output is then obtained as:

$$
P_{t}=\left(m_{a}(1+\omega)+m_{f}\right) C_{p g}\left(T_{03}-T_{04}\right)
$$

Where $\mathrm{T}_{04}$ is the stack temperature, ${ }^{\circ} \mathrm{C}$.

Using the isentropic relation, the temperature gradient across the turbine is obtained as:

$$
T_{03}-T_{04}=\mathrm{y}_{T} T_{03}\left(1-\left(\frac{P_{4}}{P_{3}}\right)^{\frac{\gamma_{g}-1}{\gamma_{g}}}\right)
$$

Where $\eta_{T}$ is the isentropic efficiency of the gas turbine and $\gamma_{g}$ is the specific heat capacity of the products of combustion. The turbine inlet pressure, $\mathrm{P}_{3}$, can be calculated as [19]:

$$
P_{3}=P_{2}-\Delta P_{c o}
$$

where, $\Delta P_{c o}$ equals pressure drop in the combustor, and is usually within $2 \%-5 \%$ of $P_{2}$ [13].

And the net power developed by the plant is then:

$$
P_{n}=P_{t}-P_{c}
$$


Substituting equation (11) and equation (23) into equation (26), the net power developed by a gas turbine in terms of inlet temperature and specific humidity is [20]:

$$
\begin{aligned}
P_{n}=\left(m_{a}(1+\omega)+m_{f}\right) C_{p g}\left(T_{03}-T_{04}\right) & \\
& -m_{a}(\omega+1) C_{p m a}\left(T_{02}-T_{01}\right)
\end{aligned}
$$

The thermal efficiency is:

$$
\mathrm{y}_{t h}=\frac{P_{n}}{m_{f} F H V}
$$

The heat rate, $H R$, is obtained from [21]:

$$
H R=\frac{Q}{P_{n}}
$$

\section{METHODOLOGY}

The dry and wet bulb temperatures were obtained from the turbine plant environment with the aid of the microprocessor base digital psychrometer 8706 , as shown in figure 3 from which the psychrometrics properties where computed.

The models generated were converted into MATLAB programs, that generate pictorial representation of solutions to help in understanding the performance of the gas turbine plants under varying conditions of the atmosphere. The basic gas turbine parameters employed are those of Transcorp Power Plant in Ughelli, Delta State, Nigeria. The simulation assumes ideal conditions for the turbine and compressor work transfer processes.

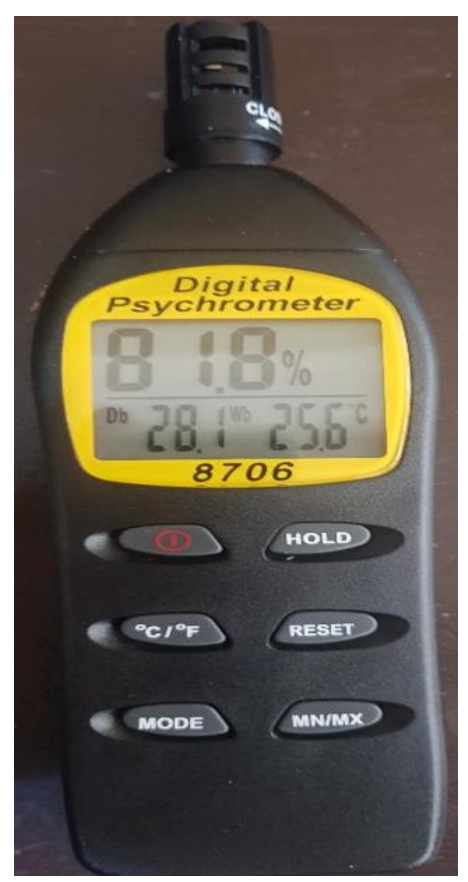

Fig. 3: Microprocessor 8706 Digital Psychrometer

\section{RESULTS AND DISCUSSION}

\subsection{Psychrometric Graphics}

Figure 4 shows a plot of dry and wet bulb temperature against time of the day. The variability of the environment is quite evident with changes in time. The changes are largely due to the earth rotation. Using Carrier's equation, the variability of the partial pressure of vapour with changes in time is obtained as shown in figure 5 .

Figure 6 shows a plot of variability of moisture content with changes of time due to the earth rotation while figure 7 is a plot of variability of degree of saturation with changes in time occasioned by the earth rotation.

As clearly seen the atmospheric conditions is dynamic and as such gas turbine performance metric is expected to be dynamic in nature.

\subsection{Gas turbine performance Metric}

\subsubsection{Compressor Power Consumption}

Figure 8 represents a plot of compressor power consumption against dry bulb temperature at various humidity ratio.

The plot shows that the compressor power increases as the dry bulb temperature increases, and also increases with an increase in moisture content. This is because as temperature rises, the molecules in air separate further and are more energetic, thus requiring more power to compress them. Similar results were obtained by $[13,21]$.

\subsubsection{Turbine Net Power Output}

Figure 9 shows plot of net power output against dry bulb temperature at various humidity contents. The plot shows that the net power output of the turbine decreases with an increase in the dry bulb temperature, and also increases with an increase in moisture content. Higher dry bulb temperature leads to a lower air density and thus a higher compressor work. 


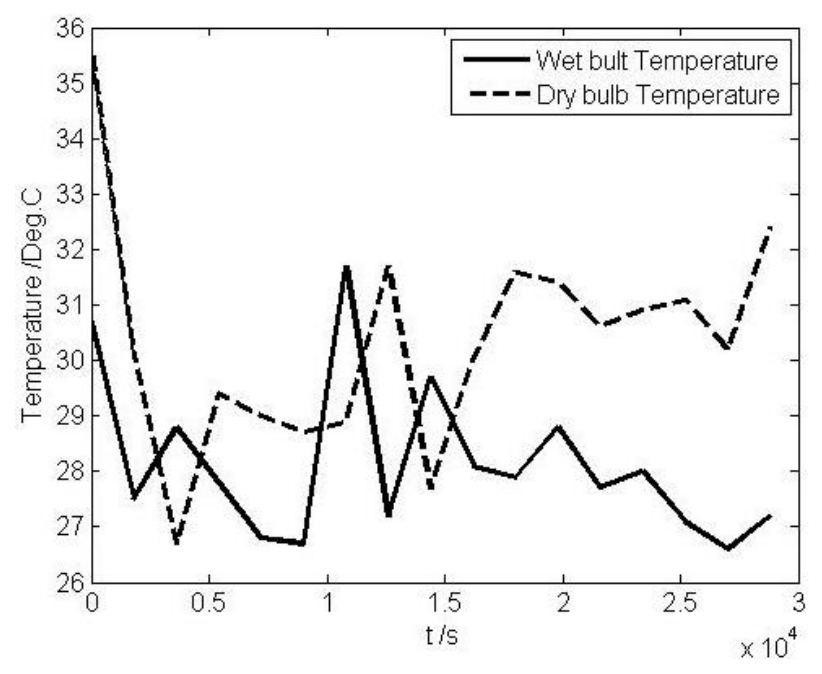

Fig. 4: Plot of Dry and Wet bulb temp. vs time

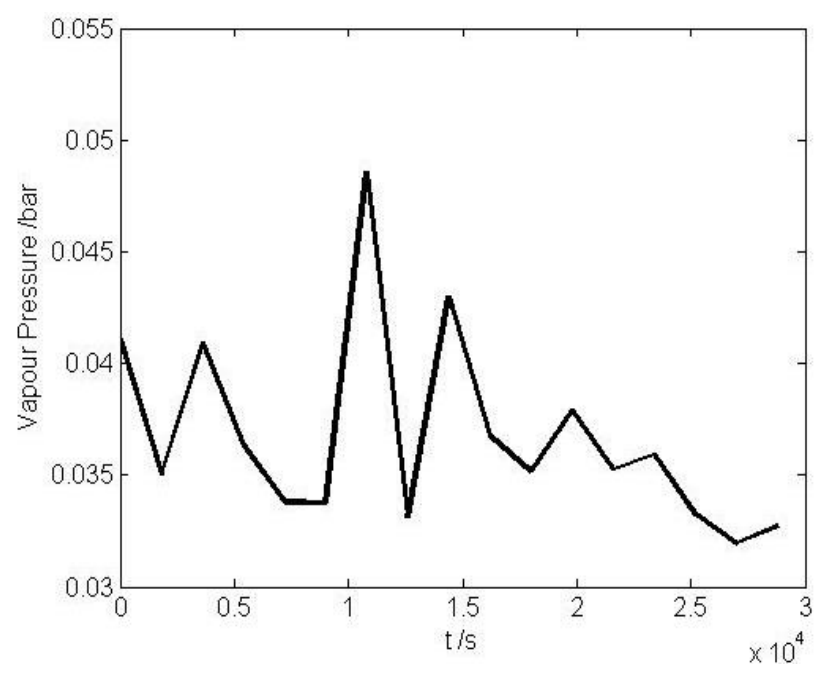

Fig. 5: Plot of Vapour pressure vs time

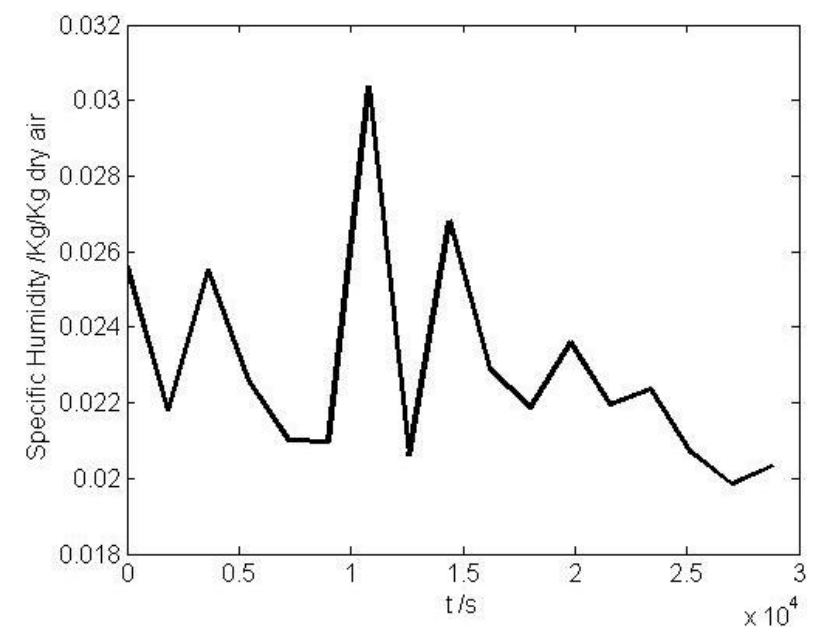

Fig. 6: Plot Specific humidity vs time

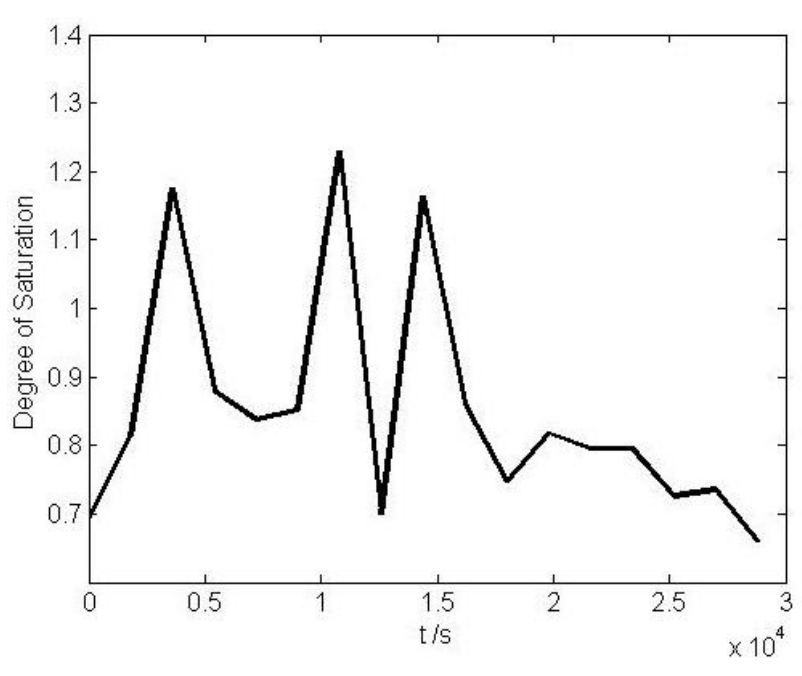

Fig. 7: Plot of Degree of saturation vs time

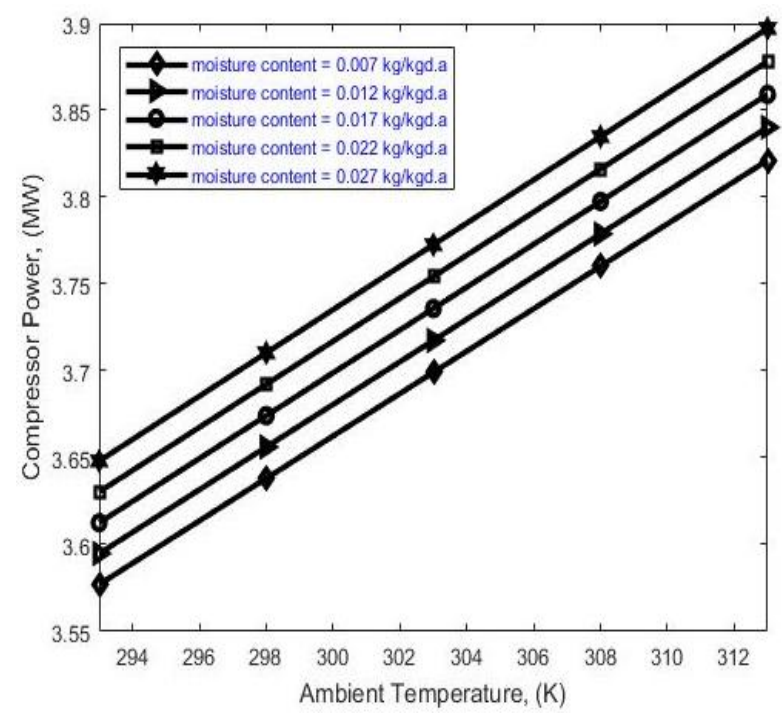

Fig. 8: Compressor power consumption vs dry bulb temperature

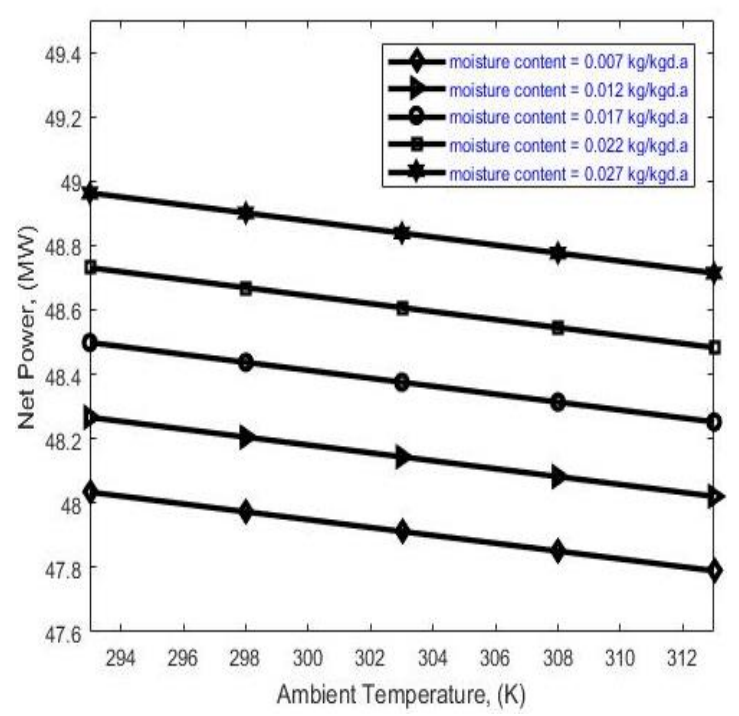

Fig. 9: Turbine net power output vs dry bulb temperature 


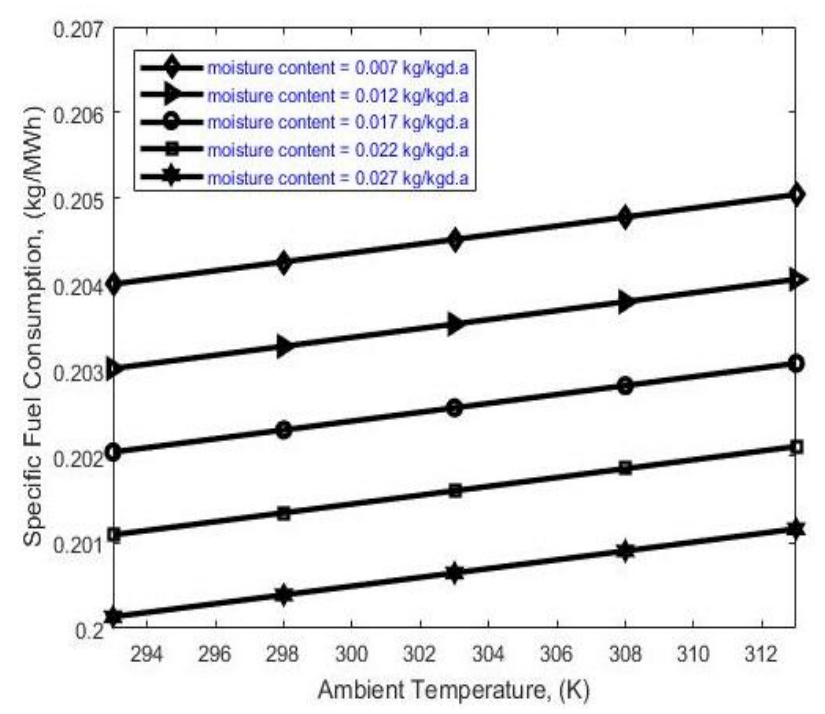

Fig. 10: Specific Fuel Consumption vs dry bulb temperature

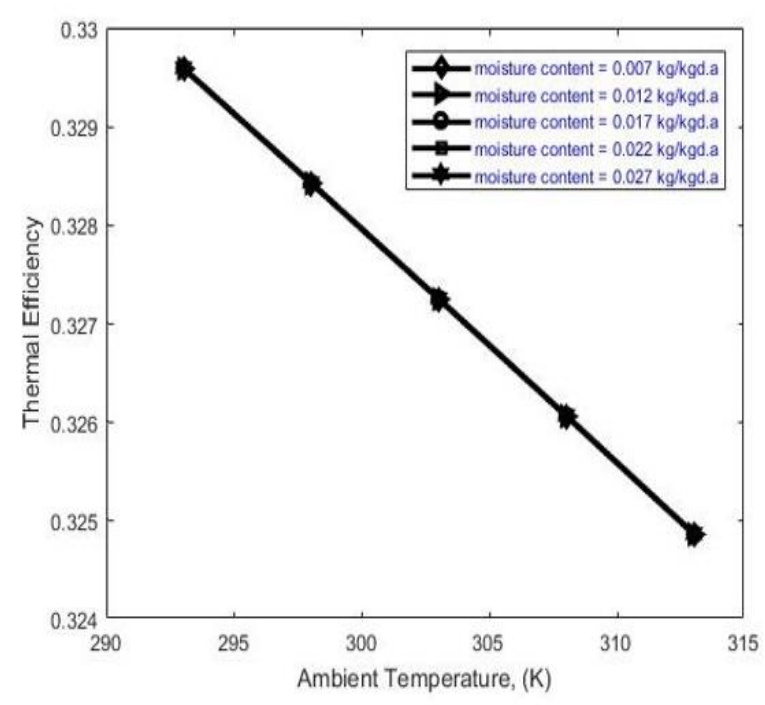

Fig. 11: Thermal Efficiency vs dry bulb temperature

Although increasing the moisture content leads to an increase in both turbine power and compressor power, the increase in turbine power is more than that of the compressor power thus leading to an increase in net power. Similar results were obtained by $[1,13,22]$.

\subsubsection{Specific Fuel Consumption}

Figure 10 shows a plot of specific fuel consumption against dry bulb temperature at different humidity ratios.

The plot shows that the Specific Fuel Consumption increases as the dry bulb temperature increases but decreases as moisture content increases. The air mass flow rate entering the compressor increases with a decrease in dry bulb temperature and decreases with an increase in moisture content, similar results were obtained by [1], [21], [23].

\subsubsection{Thermal Efficiency}

Figure 11 shows a plot of thermal efficiency against dry bulb temperature at different humidity contents. Clearly the thermal efficiency decreases as dry bulb temperature increases, but shows little changes with changes in moisture content with extrapolation of the efficiency curves. This increase of efficiency as a result of decrease in moisture content and ambient temperature is due to the low compressor power consumption by the compressor, similar results were also obtained by $[21,23]$.

\section{CONCLUSIONS}

Ensuring gas turbine run at maximum efficiency is a primary goal for operators. From an environmental point of view, it is important that turbines run efficiently and emit fewer emissions. The gas turbine was critically analysed from the point of view of environmental conditions of dry bulb temperature and moisture contents. The results pointed clearly that compressor power consumption increased by $1.65 \%$ for $0.7 \%$ rise in ambient temperature, and $0.50 \%$ for $71.4 \%$ rise in moisture content. The specific fuel consumption also increased with increase in ambient temperature, a $1.71 \%$ rise in ambient temperature resulted in a $0.15 \%$ rise in specific fuel consumption but it decreased by $0.49 \%$ for a $41.7 \%$ rise in moisture content. A $1.62 \%$ rise in ambient temperature led to a $0.13 \%$ drop in net power and a $29.4 \%$ rise in moisture content resulted in a $0.48 \%$ drop in net power output. The effect of variation of heat rate, work ratio and thermal efficiency is more significant with changes in ambient temperature than in humidity ratio.

\section{REFERENCES}

[1]. Rahman M. M., Ibrahim T. K., Kadirgama K., Mamat R. and Bakar R. A., (2011a). "Influence of Operation Conditions and Ambient Temperature on Performance of Gas Turbine Power Plant", Advanced Materials Research, Volume 189, Issue 193, Pages 3007-3013.

[2]. Horlock J. H. (2003). "Advance Gas Turbine Cycles", first edition, Pergamon Press Oxford, UK. Pp. 7. 
[3]. El-Hadik A. A., (1990). The Impact of Atmospheric Conditions on Gas Turbine Performance. Journal of Engineering for Gas Turbines and Power, The American Society of Mechanical Engineers, Vol. 112, issue 4, pp. 590-596.

[4]. Mohanty B., Paloso G., (1995). "Enhancing Gas Turbine Performance by Intake Air Cooling Using an Absorption Chiller", Heat Recovery Systems and CHP, Vol. 15, issue 1, pp. 41-50.

[5]. Pyzik E., Jarzebowski S., Miller A., (2012). "Impact of inlet air cooling on gas turbine performance", Journal of Power Technologies, Vol. 92 issue 4, pp. 249-257.

[6]. Taniguchi H., Miyamae S., Arai N. Lior N. (2000). "Power Generation Analysis for HighTemperature Gas Turbine in Thermodynamic Process", Journal of Propulsion and Power, Aerospace Research Central. Vol. 16, issue 4, pp. 557-561.

[7]. Gatley D. P. (2012). "Understanding Psychrometrics", third Edition. ASHRAE Inc. pp. $31-47,107-153$.

[8]. Rogers G., Mayhew Y. (1992) "Engineering Thermodynamics Work and Heat Transfer" Pearson Education, Fourth Edition, pp. 248254.

[9]. Desai P. S. (2017) "Refrigeration and Air conditioning for Engineers" Khanna Publishers Part II pp. 4-27.

[10]. Alhazmy M. M., Najjar Y. S. H., (2004). "Augmentation of Gas Turbine Performance Using Air Coolers", Applied Thermal Engineering, Vol. 24, issues 2-3, pp. 415-429.

[11]. Ameri M., Hejazi S. H., (2004). "The Study of Capacity Enhancement of the Chabahar Gas Turbine Installation Using an Absorbtion Chiller", Applied Thermal Engineering, Vol. 24, issue 1 , pp. 59-68.

[12]. Arangi H. G., Sivaram P., HariBabu N. (2015). "Analysis of Inlet Air Temperature Effect on Gas Turbine Compressor Performance", International Research Journal of Engineering and Technology, Vol. 2, issue 8, pp. 845-853.

[13]. Ranjan R., Tariq M., (2014). "Analysis of A Regenerative Gas Turbine Cycle for Performance Evaluation", International Journal of Engineering Research and General Science, Vol. 2 issue 4, pp. 792-801.

[14]. Eastop T. D., McConkey A. (2004) "Applied Thermodynamics for Engineering Technologists"Tata McGraw Hill, pp. 260-265.
[15]. Cengel A. Y., Boles A. M. (2008). "Thermodynamics an Engineering Approach", fifth edition. McGraw-Hill, New York, pp. 236, 508.

[16]. Coren H., Rogers G. F.C., Saravanamuttoo H. I.H. (1987). "Gas Turbine Theory" Longman Scientific and Technical, Third Edition pp. 3349.

[17]. Farouk N. M., Sheng L., Hayat Q. (2013). "Effect of Ambient Temperature on the Performance of Gas Turbines Power Plant", International Journal of Computer Science Issues, Vol. 10, issue 1, pp. 439-442.

[18]. Boyce M. P. (2002). "Gas Turbine Engineering Handbook", second edition, Gulf Professional Publishing, pp. 221-223, 370 - 372, 692 700.

[19]. Lebele-Alawa B.T., Jo-Appah V. (2015). "Thermodynamic Performance Analysis of a Gas Turbine in an Equatorial Rain Forest Environment", Journal of Power and Energy Engineering Scientific Research Publishing Incorporated, vol. 3, issue 1, pp. 11-23.

[20]. Dawoud B., Zurigat Y. H., Bortmany J. (2005). "Thermodynamic assessment of power requirements and impact of different gasturbine inlet air cooling techniques at two different locations in Oman", Applied Thermal Engineering, vol. 25 issue 11-12, pp. 15791598.

[21]. Rahman M. M., Ibrahim T. K., Abdalla A. N. (2011b). "Thermodynamic performance analysis of gas-turbine power-plant", International Journal of Physical Sciences, Academic Journals, vol. 6, Issue 14, Pages 3539-3550.

[22]. Oyedepo S. O., Kilanko O. (2014). "Thermodynamic Analysis of a Gas Turbine Power Plant Modeled with an Evaporative Cooler", International Journal of Thermodynamics, vol. 17, issue 1, pp. 14-20.

[23]. Igoma E. N., Lebele-Awala B. T., and Sodiki J. (2014). "Evaluation of the Influence of Ambient Temperature on the Performance of the Trans-Amadi Gas Turbine Plant". Journal of Power and Energy Engineering, vol.4, issue 11, pp. 19-31. 